\title{
Hypoxia increases Hsp90 binding to eNOS via PI3K-Akt in porcine coronary artery endothelium
}

\author{
Jian-xiong Chen ${ }^{1}$ and Barbara Meyrick ${ }^{1,2}$ \\ ${ }^{1}$ Department of Pathology and ${ }^{2}$ Department of Medicine, Vanderbilt University Medical Center, Nashville, \\ TN, USA
}

\begin{abstract}
This study examines the molecular mechanisms by which hypoxia regulates phosphorylated endothelial nitric oxide synthase (eNOS) activity and NO production in porcine coronary artery endothelial cells (PCAEC). Exposure to hypoxia $\left(\mathrm{pO}_{2}=10 \mathrm{mmHg}\right)$ for periods up to $3 \mathrm{~h}$ resulted in a time-dependent increase in eNOS protein expression and an early $(15 \mathrm{~min})$ and sustained increase in eNOS phosphorylation at Ser-1177. Exposure to hypoxia for $30 \mathrm{~min}$ led to a doubling in eNOS activity (control $=6.2 \pm 4.4$ vs hypoxia $=14.1 \pm 5.0 \mathrm{fmol}$ cGMP $/ \mu \mathrm{g}$ protein, $P<0.05$ ) and NO release (control $=5.9 \pm 0.8$ vs hypoxia $=11.8 \pm 1.2 \mathrm{nM} / \mu \mathrm{g}$ protein, $P<0.05$ ). Hypoxia also led to a significant increase in Akt phosphorylation and upregulation of Hsp9O binding to eNOS. Pretreatment of cells with either $1 \mu \mathrm{g} / \mathrm{ml}$ geldanamycin (a specific inhibitor of Hsp90) or $500 \mathrm{nM}$ wortmannin (a specific PI3 kinase inhibitor) suppressed hypoxia-stimulated Akt and eNOS phosphorylation and significantly attenuated hypoxia-stimulated Hsp90 binding to eNOS. Both eNOS activity and NO production were inhibited by geldanamycin and wortmannin. Although hypoxia led to early activation of p42/44 mitogen-activated protein kinases (MAPK), inhibition of their pathway by PD98059 did not suppress hypoxia-stimulated eNOS phosphorylation and eNOS activity. These data demonstrate that hypoxia leads to increased eNOS phosphorylation via stimulated Hsp90 binding to eNOS and activation of the PI3-Akt pathway. We conclude that a coordinated interaction between Hsp90 and PI3-Akt may be an important mechanism by which eNOS activity and NO production is upregulated in hypoxic heart.
\end{abstract}

Laboratory Investigation (2004) 84, 182-190, advance online publication, 8 December 2003; doi:10.1038/labinvest.3700027

Keywords: phosphorylated endothelial nitric oxide synthase (eNOS); Akt phosphorylation; cardiac ischemia

The endothelium plays an important role in regulating vascular tone in normal and disease states by release of endothelium-derived vasodilators, the most important of which is nitric oxide (NO). In the endothelium, NO is endogenously produced from the terminal guanido nitrogen of L-arginine by the endothelial isoform of nitric oxide synthase (eNOS). ${ }^{1}$ eNOS is highly regulated by various stimuli such as shear stress and growth factors, for example, vascular endothelial growth factor (VEGF). ${ }^{2,3}$ Hypoxia is also known to increase coronary blood flow via an increase in eNOS activity and NO production. ${ }^{4,5}$ Both translational and/or post-traslational mechanisms contribute to this increase. For example, using cultured bovine aortic

Correspondence: B Meyrick, Center for Lung Research, Vanderbilt University Medical Center, MCN T-1217, Nashville,TN 372322650, USA.

E-mail: Barbara.meyrick@vanderbilt.edu

Received 28 July 2003; revised 07 October 2003; accepted 20 October 2003; published online 8 December 2003 endothelial cells, hypoxia has been shown to increase eNOS mRNA and protein expression and to increase basal and bradykinin-stimulated NO production. ${ }^{6}$ However, in cultured porcine coronary microvascular endothelial cells, hypoxia has been found to increase eNOS activity and NO production without altering eNOS mRNA expression. ${ }^{7}$ To date, little is known about the molecular mechanisms by which hypoxia regulates eNOS activity and NO production in coronary artery endothelium.

eNOS has been shown to be regulated by multiple factors including: post-translational phosphorylation; $;^{8}$ availability of cofactors and substrates; ${ }^{9}$ alterations in subcellular localization; ${ }^{10}$ and protein-protein interactions such as binding to calcium-dependent calmodulin and caveolin-1. ${ }^{11,12}$ Recently, stimulation of human umbilical vein endothelial cells with VEGF and shear stress were found to increase heat-shock protein 90 (Hsp90) binding to eNOS. This increase was attributed to eNOS phosphorylation as well as increases in eNOS 
activity and NO production. ${ }^{13-16}$ While it is known that hypoxia induces multiple vascular growth factors including VEGF and upregulates Hsp90 expression in various cell types including endothelial cells, ${ }^{17,18}$ the role of hypoxia on Hsp90 binding to eNOS and eNOS phosphorylation in coronary artery endothelium has not been examined.

Activation of phospho-inositide-3 kinase (PI3 kinase) and protein kinase B/Akt signaling in endothelial cells have been shown to result in vessel relaxation via increases in eNOS activity. ${ }^{19-21}$ In rat aorta, inhibition of the PI3 kinase/Akt pathway, by its specific inhibitors wortmannin or LY294002, inhibited vessel relaxation to isoproterol. ${ }^{20}$ Further, activation of PI3 kinase/Akt pathway was demonstrated to be involved in VEGF- and shear-stressinduced eNOS phosphorylation. ${ }^{22,23}$ It is becoming increasingly clear that VEGF and shear stress stimulate PI3 kinase activation, which in turn activates Akt phosphorylation and is responsible for regulating eNOS phosphorylation at Ser-1177 and NO production..$^{24,25}$ Whether such a cascade is also invoked in coronary artery endothelial cells exposed to hypoxia is not known.

The present study uses porcine coronary artery endothelial cells (PCAEC) to examine whether hypoxia regulates eNOS activity and NO production by increasing Hsp90 binding to eNOS. Further, we examine the relationship between Hsp90, Akt and p42/44 mitogen-activated protein kinases (MAPK) in hypoxia-induced eNOS phosphorylation. Our results suggest that a coordinated interaction between Hsp90 and Akt modulates hypoxia-induced eNOS phosphorylation and activity. This interaction is MAPK independent.

\section{Materials and methods}

\section{Culture of Coronary Artery Endothelial Cells}

Coronary arteries were isolated from normal pig hearts $(n=5)$ under aseptic conditions. Endothelial cells were removed from the luminal surface of the coronary arteries with a sterile cotton bud. Cells attached to the cotton bud were agitated in growth medium and the 'loosened' cells were cultured. Single colonies of cells were subcultured in MEM supplemented with $10 \%$ fetal bovine serum (FBS), $2 \mathrm{mM}$ glutamine, $50 \mathrm{U}$ of penicillin $\mathrm{G}$, and $0.05 \mathrm{mg} / \mathrm{ml}$ streptomycin (Gibco Laboratories, Grand Island, NY, USA) at $37^{\circ} \mathrm{C}$ in a humidified $95 \%$ air $-5 \% \mathrm{CO}_{2}$ incubator. Each of the endothelial lines used in these experiments had a typical cobblestone morphology, showed uptake of acetylated low-density lipoprotein, and exhibited factor VIII-related antigen. Primary cultures of PCAEC, between passages 5 and 10, were used in all experiments.

\section{Hypoxic Exposure}

PCAEC were grown to near confluence in $100 \mathrm{~mm}$ dishes. All cells were cultured overnight in $0.4 \%$ FBS in MEM prior to the start of the experiment. For the hypoxic experiments, cell cultures were placed in a hypoxic atmosphere (modular incubator chamber, Billups-Rothenburg, Inc., Del-Mar, CA, USA) and flushed with a gas mixture of $5 \% \mathrm{CO}_{2} / 95 \% \mathrm{~N}_{2}$ for $15 \mathrm{~min}$ at $3 \mathrm{l} / \mathrm{min}^{26}$ The airtight chamber containing the cell cultures was incubated for periods of up to $3 \mathrm{~h}$ at $37^{\circ} \mathrm{C}$. Using this method, the $\mathrm{pO}_{2}$ of the media was verified to be $10 \mathrm{mmHg}$ with a standard blood/gas analyzer, and was similar to that previously described. ${ }^{7,26}$

\section{Pharmacological Interventions}

The following pharmacological inhibitors were used in these studies: the ansamycin antibiotic, geldanamycin, a well-recognized and specific inhibitor of Hsp90 (GA, $1 \mu \mathrm{g} / \mathrm{ml}$, Sigma Chemical Co, MO, USA $),{ }^{27}$ PI3K inhibitor wortmannin $(500 \mathrm{nM}$, Sigma Chemical Co, MO, USA), p42/44-specific inhibitor PD98059 $\left(25 \mu \mathrm{M}\right.$, Calbiochem, CA, USA) ${ }^{28}$ L-arginine (L-Arg, $1 \mathrm{mM}$, Calbiochem, CA, USA) and $N^{G_{-}}$ monomethyl-L-arginine (L-NMMA, $250 \mu \mathrm{M}$, Calbiochem, CA, USA). Each of the interventions was dissolved in $0.4 \%$ FBS in MEM and was added to the cells $30 \mathrm{~min}$ prior to initiation of hypoxia.

\section{Western Blot Analysis}

PCAECs were lysed in $300 \mu \mathrm{l}$ of lysis buffer $(50 \mathrm{mM}$ Tris, pH 7.4, $1 \%$ Triton X-100, $0.25 \%$ Na deoxycholate, $150 \mathrm{mM} \mathrm{NaCl}, 1 \mathrm{mM}$ EGTA, $1 \mathrm{mM}$ PMSF, $1 \mathrm{mM}$ $\mathrm{NaF}, 10 \mu \mathrm{g} / \mathrm{ml}$ aprotinin, $1 \mu \mathrm{g} / \mathrm{ml}$ leupeptin, and $1 \mathrm{mM}$ orthovanadate). Total protein concentration was determined with BCA protein assay kit (Pierce Co, IL, USA). A measure of $10 \mu \mathrm{g}$ proteins was subjected to SDS-PAGE on $12 \%$ polyacrylamide gels and transferred to nitrocellulose membranes. Immunoblotting was performed with mouse anti-eNOS (1:2500, BD Transduction Laboratories, CA, USA), mouse anti-phospho-p42/44 (1:500, Santa Cruz Biotech, CA, USA) or rabbit anti-phospho-Akt antibody (1:1000 dilution, Santa Cruz Biotech, CA, USA), for $1 \mathrm{~h}$ at room temperature. The membrane was then washed and incubated with horseradish peroxidase-conjugated goat anti-mouse IgG (1:4000 for eNOS, 1:1000 for phospho-p42/44, BD Transduction Laboratories, CA, USA) or horseradish peroxidase-conjugated anti-rabbit IgG (1:2000 dilution, Promega Co, MI, USA). Total levels of Akt and p42/44 were detected using anti-Akt (1:1000, Cell Signaling Technology, MA, USA) or anti-p42/44 (1:500, Santa Cruz Biotech, CA, USA). The membranes were developed using the Western Blot Chemiluminescence Detection Reagent (PerkinElmer, Life Science Products, MA, USA), and 
densitometric analysis was carried out using an imager and densitometer (BioRad, CA, USA) and molecular analysis software.

\section{Immunoprecipitation of eNOS and Blotting with Phospho-eNOS and Hsp90}

Endothelial cells were washed and incubated in lysis buffer containing $20 \mathrm{mM}$ Tris- $\mathrm{HCl}(\mathrm{pH}, 7.4)$, $150 \mathrm{mM} \mathrm{NaCl}, 1 \mathrm{mM}$ EGTA, $1 \mathrm{mM}$ EDTA, 1\% Triton $\mathrm{X}-100,1 \mathrm{mM}$ PMSF, $1 \mathrm{mM} \mathrm{NaF}, 10 \mu \mathrm{g} / \mathrm{ml}$ aprotinin, $1 \mu \mathrm{g} / \mathrm{ml}$ leupeptin, and $1 \mathrm{mM}$ orthovanadate for $30 \mathrm{~min}$ on ice and briefly sonicated. Immunoprecipitation was carried out by incubating the lysates with eNOS monoclonal antibody $(2 \mu \mathrm{g} / \mathrm{mg}$ of total cell protein) for $16 \mathrm{~h}$ at $4^{\circ} \mathrm{C}$, followed by a 2 -h incubation with 1:1 protein A:protein G-sepharose slurry. Following centrifugation, the immunoprecipitates were washed with lysis buffer, resuspended in loading buffer, boiled for $5 \mathrm{~min}$, and subjected to SDS-PAGE on $12 \%$ polyacrylamide gels and transferred to a nitrocellulose membrane. The primary antibodies used for immunoblotting were antiphospho-eNOS (1:1000 Cell Signaling Technology, MA, USA) or anti-Hsp90 (1:500, BD Transduction Laboratories, CA, USA). The membrane was then washed and incubated with secondary antibodies coupled to horseradish peroxidase and processed as above.

\section{Measurement of NO Synthase Activity}

Endothelial cells were grown to confluence in sixwell plates and exposed to hypoxia for $30 \mathrm{~min}$. The endothelial cells were then washed twice with HEPES buffer, pH 7.4, lysed in $500 \mu \mathrm{l}$ lysis buffer (pH. 7.0) containing $50 \mathrm{mM}$ Tris-HCl, $1 \mu \mathrm{M}$ leupeptin, $1 \mu \mathrm{M}$ pepstatin, $0.1 \mu \mathrm{M}$ PMSF, $0.5 \mathrm{mM}$ EDTA, $0.5 \mathrm{mM}$ EGTA and $12.5 \mathrm{mM}$ 2-mercaptoethanol and frozen immediately in liquid nitrogen. The lysed cells were thawed, scraped from the wells, homogenized and centrifuged at $20000 \mathrm{~g}$ for $20 \mathrm{~min}$. The pellet was washed and suspended in lysis buffer and homogenized again. NOS activity was measured as an increase in cGMP using a fibroblast-reporter cell line (RFL-6) as previously described. ${ }^{29}$ Briefly, RFL-6 cells in six-well plates $\left(1 \times 10^{6}\right.$ cells/well $)$ were incubated for $20 \mathrm{~min}$ at $37^{\circ} \mathrm{C}$ in HEPES. A $500 \mu \mathrm{l}$ aliquot of cell particulates from each of the samples (see above) was added to the RFL-6 cells and the mixture was incubated for a further $5 \mathrm{~min}$. The supernatant was then removed and the fibroblasts were frozen in liquid nitrogen. For assay, the fibroblasts were thawed on ice and $1 \mathrm{ml}$ of ice-cold $70 \%$ ethanol was added to the cells. The cells were then scraped and centrifuged at $600 \mathrm{~g}$ for $10 \mathrm{~min}$. The supernatant was transferred to microcentrifuge tubes, heated for $2-3 \mathrm{~h}$ in a spin-vacuum and cGMP levels were measured using a cGMP enzyme immunoassay (EIA) system (Amersham Pharmacia
Biotech, NY, USA). The protein concentration of each sample was measured using a BCA protein assay kit (Pierce Co, IL, USA). Each assay was carried out in duplicate. The results were expressed as fmoles cGMP/ $\mu \mathrm{g}$ protein.

\section{Measurement of NO}

Endothelial cells were grown to confluence in sixwell plates and exposed to hypoxia for $30 \mathrm{~min}$. At the end of this time, NO release was measured using a nitrate/nitrite colorimetric assay kit (Cayman Chemical Co, MI, USA). Briefly, cell culture supernatants were incubated with nitrate reductase for $3 \mathrm{~h}$ to convert nitrates into nitrites. The total amount of NO was then determined using the Griess reagent. A standard curve of nitric oxide was determined using known concentrations of nitrates, and the sample NO concentrations were calculated using the standard curve. Each assay was conducted in duplicate and the results were expressed as $\mathrm{nM} / \mu \mathrm{g}$ protein in the cells.

\section{Statistical Analysis}

The densitometric values of the protein bands obtained following treatment with the pharmacological interventions were normalized to the normoxic controls. The results are expressed as the mean \pm s.e.m. Statistical analysis was performed using oneway ANOVA followed by the Duncan's multiplecomparison test. A $P$-value $<0.05$ was taken as significant.

\section{Results}

\section{Hypoxia Stimulates eNOS Phosphorylation at Ser-1177 and Increases eNOS Activity and NO Release}

Exposure to hypoxia for various time periods (15 and $30 \mathrm{~min}, 1,2$ and $3 \mathrm{~h}$ ) resulted in a timedependent increase in eNOS phosphorylation at Ser-1177. Phosphorylated eNOS was apparent at $15 \mathrm{~min}$ of hypoxia, peaked at $30 \mathrm{~min}$ and gradually decreased over the $3 \mathrm{~h}$ of the study although still remaining higher than at baseline (Figure 1a). Since phosphorylated eNOS at Ser-1177 has been shown to correlate directly with eNOS activity and NO production, alteration in eNOS activity in response to hypoxia was measured. Thirty minutes hypoxia resulted in a two-fold increase in eNOS activity (control $=6.2 \pm 4.4 \quad$ vs hypoxia $=14.1 \pm 5.0 \mathrm{fmol}$ $\mathrm{cGMP} / \mu \mathrm{g}$ protein, $n=6, P<0.05)$ and a doubling in NO release into the culture media (control= $5.9 \pm 0.8$ vs hypoxia $=11.8 \pm 1.2 \mathrm{nM} / \mu \mathrm{g}$ protein, $n=8, P<0.05)$. The increase in hypoxia-induced NOS activity and NO release was ablated by pretreatment with L-NMMA; pretreatment with L-arginine had little effect on NOS activity and NO release (data not shown). 
Exposure to hypoxia also caused a time-dependent increase in eNOS protein expression (Figure 1b). Densitometric analysis revealed a $50 \%$ increase in eNOS protein at $30 \mathrm{~min}$ as compared to controls and gradually increased over the $3 \mathrm{~h}$ of exposure. Pretreatment with either L-NMMA or L-arginine failed to alter hypoxia-stimulated eNOS expression.

\section{Hypoxia Upregulates Phosphorylated eNOS and Increases Hsp9o Binding to eNOS}

To determine the mechanism(s) by which hypoxia regulates eNOS phosphorylation, we examined whether exposure to hypoxia increases Hsp90 binding to eNOS and whether Hsp90 mediates hypoxia-induced eNOS phosphorylation. We first performed experiments to examine the time course of Hsp90 binding to eNOS by immunoprecipitation with an eNOS antibody followed by immunoblotting with an Hsp90 antibody. Hsp90 binding to eNOS doubled within $15 \mathrm{~min}$ of exposure to hypoxia and remained increased over the $3 \mathrm{~h}$ of the study (Figure 2). We next examined whether disruption of Hsp90

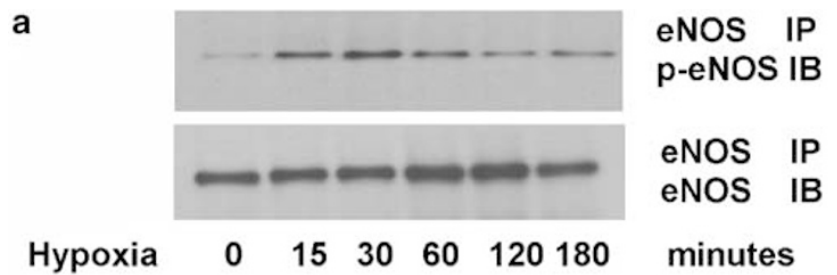

b

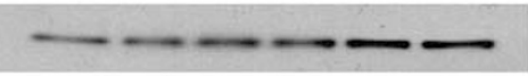

eNOS IB

\section{$\begin{array}{llllllll}\text { Hypoxia } & 0 & 15 & 30 & 60 & 120 & 180 & \text { minutes }\end{array}$}

Figure 1 (a) Representative time course of hypoxia-stimulated eNOS phosphorylation $(n=3)$. PCAECs were exposed to hypoxia for the indicated time periods, cell lysates were immunoprecipitated with eNOS antibody and immunoblotted with phosphoeNOS (Ser at 1177). Phosphorylated eNOS was apparent at $15 \mathrm{~min}$, peaked at $30 \mathrm{~min}$, and gradually declined to baseline over the $3 \mathrm{~h}$ of hypoxic exposure. (b) Representative Western blot analysis demonstrating that exposure PCAECs to hypoxia for periods up to $3 \mathrm{~h}$ caused a gradual increase in eNOS protein expression $(n=3)$.

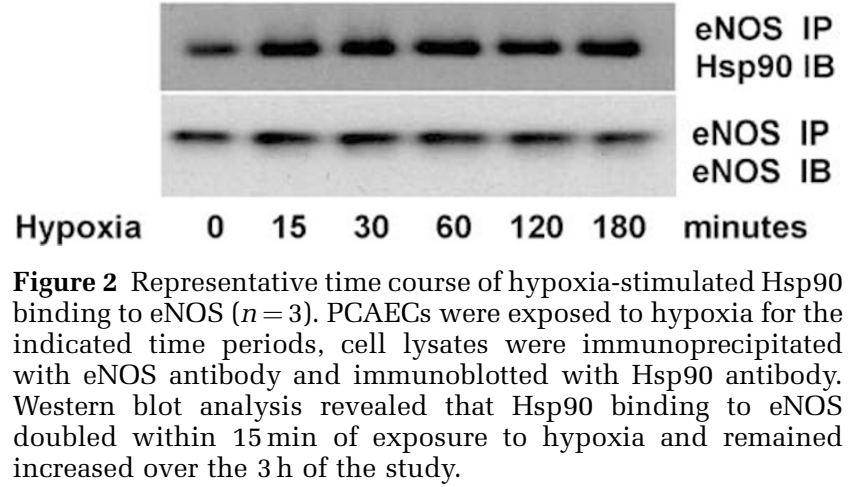

function by Hsp90 inhibitor geldanamycin would inhibit hypoxia-induced eNOS phosphorylation. Cells were pretreated with geldanamycin $(1 \mu \mathrm{g} / \mathrm{ml})$ for $30 \mathrm{~min}$ and exposed to hypoxia for $30 \mathrm{~min}$. Geldanamycin completely abolished the hypoxiainduced increase in Hsp90 binding to eNOS (Figure 3a and b). Pretreatment with geldanamycin also significantly suppressed hypoxia-stimulated eNOS phosphorylation (Figure $4 \mathrm{a}$ and b).

\section{PI3 kinase-Akt Pathway and Hypoxia-Stimulated eNOS Phosphorylation}

We next examined the time course of Akt phosphorylation in hypoxia-stimulated cells by immunoblotting PCAEC lysates with an antibody directed against phosphorylated Akt at Ser-473. By $15 \mathrm{~min}$, hypoxia caused an increase in phosphorylated Akt that was sustained at $60 \mathrm{~min}$, and decreased by 120 $180 \mathrm{~min}$ (Figure 5). Since Akt is the downstream target of PI3 kinase, we also tested whether hypoxiastimulated phosphorylation of eNOS and Akt are regulated by a PI3 kinase-dependent mechanism. Pretreatment with the PI3K inhibitor wortmannin (500 nM) completely suppressed hypoxia-stimulated eNOS phosphorylation (Figure 4a and b), and

a

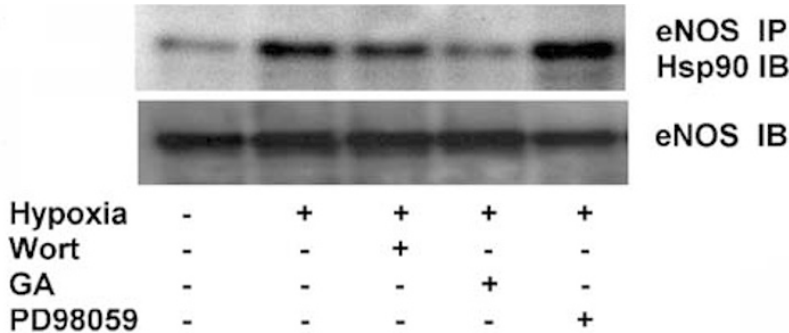

b

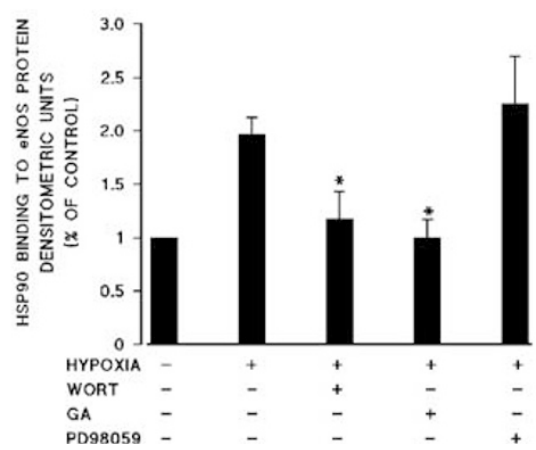

Figure 3 (a) Effect of Hsp90, PI3 kinase, and p42/44 inhibitors on hypoxia-stimulated Hsp90 binding to eNOS in PCAEC. Cells were pretreated with wortmannin (Wort, $500 \mathrm{nM}$ ), geldanymycin (GA, $1 \mu \mathrm{g} / \mathrm{ml})$, or PD98059 $(25 \mu \mathrm{M})$ for $30 \mathrm{~min}$, and then exposed to hypoxia for $30 \mathrm{~min}$. Cell lysates were immunoprecipitated with eNOS and immunoblotted with Hsp90 antibody. Western blot analysis showing that Wort and GA suppressed hypoxia-stimulated Hsp90 binding to eNOS. (b) Densitometric data from the Western blots demonstrated that pretreatment with Wort and GA resulted in significant suppression of hypoxia-stimulated Hsp90 binding to eNOS. PD98059 had little effect on hypoxia-induced Hsp90 binding to eNOS (data are normalized to control and represent the mean \pm s.d.; $n=6,{ }^{*} P<0.05$ compared to hypoxia). 


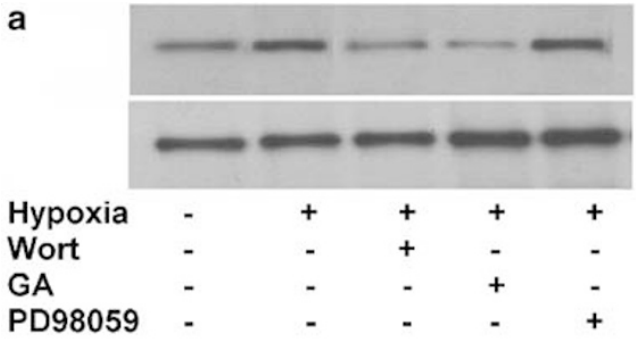

eNOS IP p-eNOS IB eNOS IB

b

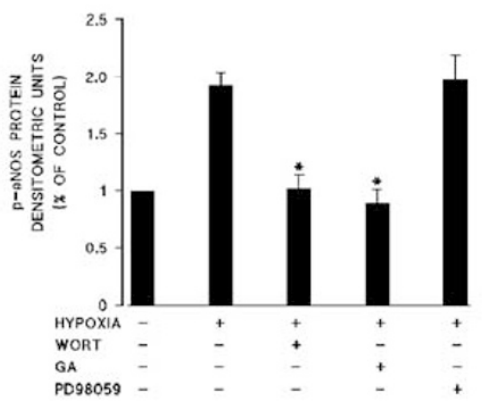

Figure 4 (a) Effect of Hsp90, PI3 kinase, and p42/44 inhibitors on hypoxia-stimulated eNOS phosphorylation in PCAEC. Cells were pretreated with wortmannin (Wort, $500 \mathrm{nM}$ ), geldanymycin (GA, $1 \mu \mathrm{g} / \mathrm{ml})$, or PD98059 $(25 \mu \mathrm{M})$ for $30 \mathrm{~min}$, and then exposed to hypoxia for $30 \mathrm{~min}$. Cell lysates were immunoprecipitated with eNOS and immunoblotted with phospho-eNOS antibody. Western blot analysis demonstrated that Wort and GA suppressed hypoxia-stimulated eNOS phosphorylation. PD98059 had little effect on hypoxia-stimulated eNOS phosphorylation. (b) Densitometric data from Western blots reveal that pretreatment with Wort and GA significantly by suppressed hypoxia-induced eNOS phosphorylation (data are normalized to control and represent the mean \pm s.d.; $n=4, \quad{ }^{*} P<0.05$ compared with hypoxia treatment).

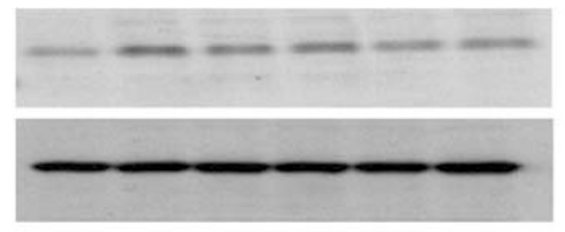

p-Akt

Akt

\section{$\begin{array}{llllllll}\text { Hypoxia } & 0 & 15 & 30 & 60 & 120 & 180 & \text { minutes }\end{array}$}

Figure 5 Representative time course of hypoxia-stimulated Akt phosphorylation in PCAEC. Exposure to hypoxia was for periods of up to $3 \mathrm{~h}$, then cell lysates were immunoblotted with an antibody directed against phosphorylated Akt at Ser-473. Hypoxia led to a dramatic increase in phosphorylation of Akt by $15 \mathrm{~min}$ that was sustained at $60 \mathrm{~min}$ and decreased by 120 and $180 \mathrm{~min}$. The total Akt level was unaltered during the $3 \mathrm{~h}$ study $(n=3)$.

this was accompanied by a significant inhibition of hypoxia-stimulated Akt phosphorylation (Figure 6a and $b)$.

\section{Interaction Between Hsp90 and PI3 Kinase-Akt Pathway in Response to Hypoxia}

To explore a possible interaction between Hsp90 and the PI3 kinase-Akt pathway in hypoxiainduced eNOS phosphorylation, the effect of the a

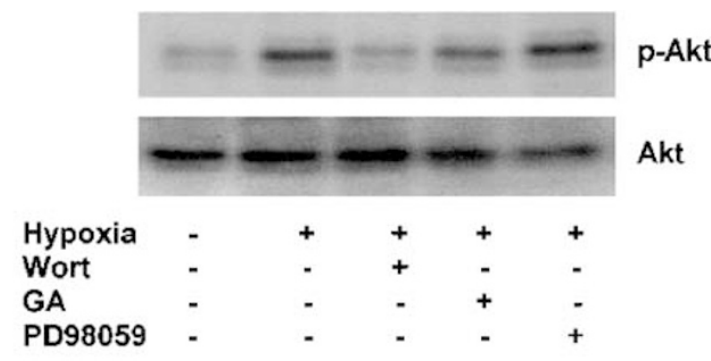

b

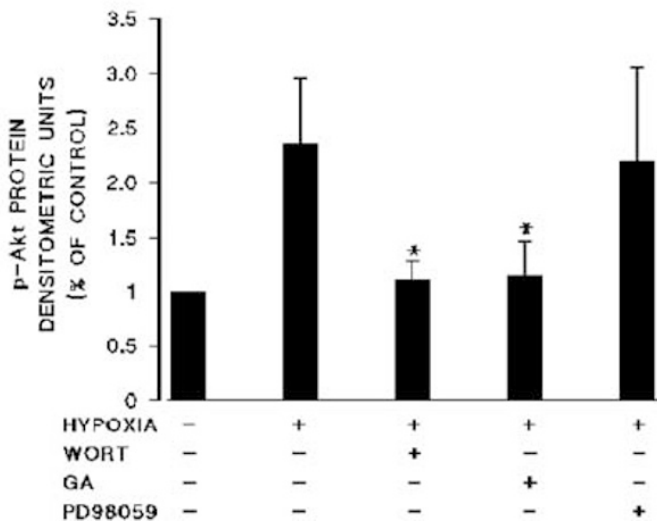

Figure 6 (a) Effect of Hsp90, PI3 kinase, and p42/44 inhibitors on hypoxia-stimulated Akt phosphorylation in PCAEC. Cells were pretreated with wortmannin (Wort, $500 \mathrm{nM}$ ), geldanymycin (GA, $1 \mu \mathrm{g} / \mathrm{ml}$ ), or PD98059 (25 $\mu \mathrm{M})$ for $30 \mathrm{~min}$, then exposed to hypoxia for $30 \mathrm{~min}$. Cell lysates were immunoblotted with phospho-Akt antibody. Western blot analysis demonstrated that Wort and GA significantly attenuated hypoxia-stimulated Akt phosphorylation. PD98059 had little effect on hypoxia-stimulated Akt phosphorylation. Total Akt level was unchanged over the $3 \mathrm{~h}$ of the exposure. (b) Densitometric data from the Western blots revealed that pretreatment with Wort and GA significantly suppressed hypoxia-induced Akt phosphorylation (data are normalized to control and represent the mean \pm s.d.; $n=3$, ${ }^{*} P<0.05$ compared with hypoxia treatment).

PI3 kinase inhibitor, wortmannin, on Hsp90 binding to eNOS was examined. PCAECs were pretreated with $500 \mathrm{nM}$ wortmannin for $30 \mathrm{~min}$ and exposed to hypoxia for periods of up to $30 \mathrm{~min}$. Cell lysates were immunoprecipitated with an antibody to eNOS and immunoblotted with an Hsp90 antibody. As shown in Figures 3a and b, wortmannin significantly suppressed the hypoxia-stimulated increase in Hsp90 protein binding to eNOS in the eNOS immunoprecipitatant. The effect of the Hsp90 inhibitor on the hypoxia-induced Akt phosphorylation was also tested. Pretreatment with geldanamycin $(1 \mu \mathrm{g} / \mathrm{ml})$ resulted in significant suppression of the hypoxia-stimulated Akt phosphorylation (Figure $6 a$ and $b)$.

\section{Role of PI3 Kinase-Akt and Hsp90 on Hypoxia- Stimulated eNOS Activity and NO Production}

We next examined the effects of the PI3 kinase-Akt pathway and Hsp90 on hypoxia-induced eNOS 
activity and NO release. PCAEC were pretreated with either $500 \mathrm{nM}$ wortmannin or $1 \mu \mathrm{g} / \mathrm{ml}$ geldanamycin for $30 \mathrm{~min}$ followed by exposure to hypoxia for $30 \mathrm{~min}$. Pretreatment with either wortmannin or geldanamycin resulted in suppression of hypoxiainduced eNOS activity $(P<0.05$, Figure $7 a)$. Hypoxia-
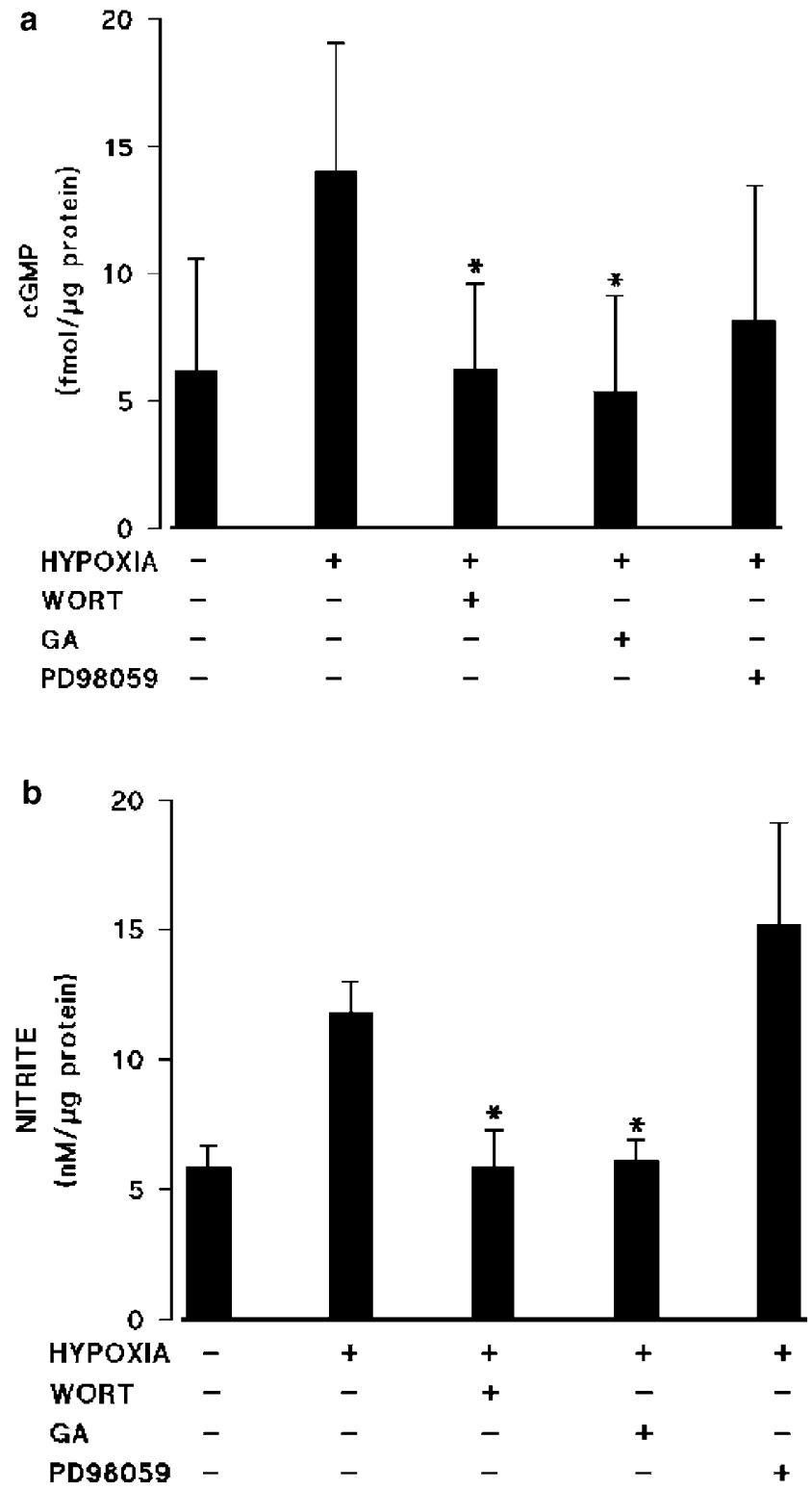

Figure 7 (a) Effect of Hsp90, PI3 kinase, and p42/44 inhibitors on hypoxia-stimulated eNOS activity. Cells were pretreated with wortmannin (Wort, $500 \mathrm{nM}$ ), geldanymycin $(\mathrm{GA}, 1 \mu \mathrm{g} / \mathrm{ml}$ ) or PD98059 $(25 \mu \mathrm{M})$ for $30 \mathrm{~min}$, followed by hypoxia for $30 \mathrm{~min}$, and then eNOS activity was measured using RFL-6 reported cell line. eNOS activity was expressed as cGMP level in the reported cells. ( $n=6,{ }^{*} P<0.05$ compared with hypoxia treatment). (b) Effect of Hsp90, PI3 kinase, and p42/44 inhibitors on hypoxiastimulated NO production. Cells were pretreated with wortmannin (Wort, $500 \mathrm{nM}$ ), geldanymycin (GA, $1 \mu \mathrm{g} / \mathrm{ml}$ ), or PD98059 $(25 \mu \mathrm{M})$ for $30 \mathrm{~min}$, followed by hypoxia for $30 \mathrm{~min}$, and total nitrite was measured as described under the 'Materials and methods'. ( $n=6,{ }^{*} P<0.05$ compared to hypoxia). stimulated NO release was also inhibited by wortmannin or geldanamycin $(P<0.05$, Figure $7 \mathrm{~b})$.

\section{Role of the MAPK p42/44 Pathway in Hypoxia Stimulated-eNOS Phosphorylation}

Since it has been demonstrated that the p42/44 pathway is also involved in eNOS phosphorylation and NO production, we next examined the role of the p42/44 pathway in regulation of the hypoxiainduced increase in eNOS phosphorylation, eNOS activity, and NO release by pharmacologically blocking the p42/44 signaling pathway. Western blot analysis showed that hypoxia increased p42/44 phosphorylation at $15 \mathrm{~min}$, phosphorylation peaked at $30 \mathrm{~min}$, and by $2 \mathrm{~h}$ had reverted to normal (Figure 8). However, the hypoxia-induced increases in eNOS and Akt phosphorylation, and eNOS-associated Hsp90 were not significantly affected by pretreatment with $25 \mu \mathrm{M}$ PD98059 (Figures 3, 4 and 6). Pretreatment with PD98059 (25 $\mu \mathrm{M})$ also had little effect on the hypoxia-induced increase of eNOS activity (Figure 7a).

\section{Discussion}

Our studies in PCAEC demonstrate, for the first time, that hypoxia stimulated eNOS phosphorylation as early as $15 \mathrm{~min}$, peaking at $30 \mathrm{~min}$ and remaining elevated for periods of up to $3 \mathrm{~h}$. A $30 \mathrm{~min}$ exposure to hypoxia also led to a doubling in eNOS activity and NO release. These hypoxia-induced increases were ablated by pretreatment with the NOS inhibitor, L-NMMA and unchanged by pretreatment with the NOS substrate, L-arginine. Our present studies also found that hypoxia induced a significant increase in Hsp90 binding to eNOS. Further, inhibition of Hsp90 significantly suppressed hypoxia-stimulated eNOS phosphorylation, eNOS activity, and NO release. Hypoxia also resulted in a time-dependent increase in Akt phosphorylation, and inhibition of PI3 kinase resulted in significant suppression of hypoxiastimulated eNOS phosphorylation and eNOS activity. In addition, our data demonstrate that inhibition of PI3 kinase-Akt pathway suppressed hypoxia-

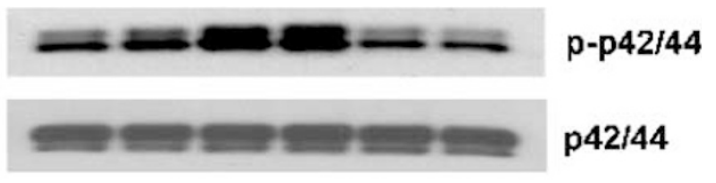

$\begin{array}{llllllll}\text { Hypoxia } & 0 & 15 & 30 & 60 & 120 & 180 & \text { minutes }\end{array}$

Figure 8 Temporal effect of hypoxia on p42/44 phosphorylation in PCAECs $(n=3)$. Western blot analysis demonstrated that hypoxia increased p42/44 phosphorylation by $15 \mathrm{~min}$, phosphorylation peaked at $30 \mathrm{~min}$ and by $2 \mathrm{~h}$ had returned to normal. The total p42/44 level remained stable during $3 \mathrm{~h}$ of hypoxia exposure. 
induced Hsp90 binding to eNOS. Hypoxia also caused activation of p42/44 MAPK. However, inhibition of this pathway had little effect on hypoxia-stimulated eNOS phosphorylation and eNOS activity.

Hypoxia affects endothelial cell physiology in various ways and regulates the synthesis and release of vasoactive substances. Hypoxia is a potent coronary vasodilator and NO is considered to be an important early mediator of this effect. Studies in PCAEC have demonstrated that hypoxia increases NO production via upregulation of eNOS activity; ${ }^{7,26}$ however, the exact mechanism(s) that underlies these increases is not known. NOS phosphorylation at Ser-1177 has been widely considered to be an important mechanism for increased NO production under various stimuli such as VEGF, shear stress. ${ }^{24,25}$ Phosphorylation of eNOS directly correlates with electron flow through the eNOS enzyme, increases in eNOS activity and NO production in the endothelial cells. ${ }^{30}$ The present study demonstrates that hypoxia stimulates phosphorylation of eNOS at Ser-1177, increases eNOS activity and NO production. We further reveal that inhibition of eNOS phosphorylation, by use of either specific PI3 kinase or Hsp90 inhibitors, significantly attenuates hypoxiainduced eNOS activity and NO production. Thus, it seems that eNOS phosphorylation at Ser-1177 is required for hypoxia-induced eNOS activation and NO production in PCAEC. L-arginine, the substrate for eNOS and the precursor for the synthesis of NO, has been reported to have beneficial effects in the coronary artery disease through improving endothelial cell function and increasing NO release. ${ }^{31,32}$ Our data demonstrate that exogenous L-arginine enhances basal NO release in PCAEC, but has little effect on hypoxia-induced eNOS activity and NO production, indicating that under our experimental conditions the substrate level is already sufficient to fuel the eNOS enzymatic activity in the setting of hypoxia.

eNOS is known as a constitutive, calcium/calmodulin-dependent enzyme, but recent studies have demonstrated that other eNOS-associated proteins may regulate eNOS function. For example, Hsp90 has long been known to affect the activity and function of some proteins by acting as a molecular chaperone and to play an important role in refolding certain denatured proteins under conditions of stress. ${ }^{33,34}$ An Hsp90/eNOS interaction is considered to be key to eNOS phosphorylation and subsequent NO production. ${ }^{35,36}$ Using COS cells, expression of Hsp90 has been shown to directly activate eNOS, and coexpression of eNOS and Hsp90 to increase NOS activity. ${ }^{13}$ In addition, pretreatment with geldanamycin has been shown to influence the conformational stability of Hsp90, ${ }^{27}$ and to attenuate histamine- and VEGF-stimulated cGMP and NO production in cultured endothelial cell through inhibition of phosphorylation of eNOS at Ser1179. ${ }^{13,15,16}$ These data highlight the importance of
Hsp90 in modulating NO release and endothelial function. Recently, Shi et $a l^{37}$ demonstrated that hypoxia increases generation of NO by increasing eNOS-associated Hsp90 in neonatal rabbit hearts. Our data are in line with those findings and further demonstrate that Hsp90 binding to eNOS, leading to eNOS phosphorylation, is key to this event.

Protein kinase B (Akt) is an important protooncogene involved in glucose metabolism and cell survival. Akt is phosphorylated via tyrosine kinase G-coupled receptors and shear stress, ultimately resulting in either protein activation or inactivation. Akt is known to phosphorylate eNOS and increase eNOS activity. ${ }^{24,25}$ Further, the PI3 kinase-AkteNOS phosphorylation signal has been reported to play a significant role in calcium-dependent (eg, VEGF) and -independent (eg, fluid shear stress) NO production. For example, it has been shown that VEGF stimulates eNOS phosphorylation, increases eNOS activity and NO production while inhibition of PI3-Akt pathway blocks VEGF-stimulated NO release in human endothelial cells. ${ }^{22,24}$ In addition, shear-stress-induced eNOS phosphorylation in cultured endothelial cells has been found to regulate PI3 kinase-Akt signaling. ${ }^{23,25}$ Further, Boo et $a l^{38}$ in bovine aortic endothelial cells demonstrated that overexpression of a constitutively active $\mathrm{Akt}^{\mathrm{Myr}}$ mutant increased phosphorylation of eNOS and NO production. These studies provide strong evidence that Akt is one of the protein kinases responsible for eNOS phosphorylation. Hypoxia upregulates genes such as Akt and VEGF, and is the major stimulus that leads to enhanced glucose metabolism and angiogenesis. ${ }^{17,39}$ The present study demonstrates that hypoxia markedly increases Akt phosphorylation, while blockade of PI3 kinase-Akt by wortmannin suppresses hypoxia-induced eNOS phosphorylation and indicates that the PI3 kinaseAkt pathway regulates hypoxia-stimulated eNOS phosphorylation and eNOS activity.

Inhibition of Hsp90 has been shown to downregulate Akt phosphorylation and Akt signaling, ${ }^{40}$ and disruption of Hsp90 function inhibits Akt phosphorylation and suppresses Akt kinase activity. ${ }^{41,42}$ In addition, it has been suggested that Akt is a substrate of Hsp90 and that Hsp90 is responsible for the stabilization of the phosph-Akt. Inhibition of Akt-Hsp90 binding leads to Akt dephosphorylation and a decrease in Akt activity. ${ }^{43}$ Consistent with those studies, our present data demonstrate that pharmacological inhibition of Hsp90 significantly inhibits hypoxia-induced Akt phosphorylation and significantly suppresses hypoxia-induced Hsp90 binding to eNOS. To our knowledge this is the first time that hypoxia-induced Akt phosphorylation has been directly correlated with increases in Hsp90 binding to eNOS. Our study in PCAECs reveals that hypoxia stimulates the formation of a stabilized multiprotein complex containing phosphorylated eNOS, Akt, and Hsp90 and suggests that a coordinated interaction between Hsp90 and Akt may be an 
important mechanism by which eNOS activity and NO production is upregulated.

It is important to emphasize that Akt is unlikely to be the only protein kinase that modulates eNOS phosphorylation. For example, it is known that activation of p42/44 MAPKs regulate eNOS phosphorylation and eNOS activity. Inhibition of p42/44 by PD98059 ${ }^{28}$ has been shown to suppress estrogeninduced eNOS activation in ovine pulmonary endothelial cells ${ }^{44}$ while in bovine aortic endothelial cells inhibition of p42/44 activity stimulated bradykinin-induced eNOS activity. ${ }^{45}$ While our study demonstrates that hypoxia resulted in an early increase in p42/44 phosphorylation, inhibition of this pathway had little effect on hypoxia-induced eNOS phosphorylation. Similar findings have also been reported for shear-stress-dependent eNOS phosphorylation and NO production. ${ }^{38,46}$

In summary, the present study demonstrates that hypoxia increases Hsp90 binding to eNOS, activates Akt, and leads to Akt-dependent eNOS phosphorylation at Ser-1177. Consistent with these findings, both eNOS enzyme activity and NO production were significantly increased in response to hypoxia. Further, disruption of Hsp90 and Akt function by Hsp90 and PI3 kinase inhibitors suppresses hypoxia-stimulated eNOS phosphorylation and NO production. Although hypoxia led to p42/44 activation, inhibition of MAP kinase pathway by specific inhibitor PD98059 did not significantly suppress hypoxia-stimulated eNOS phosphorylation and NO production. We conclude that both increased Hsp90 binding to eNOS and activation of the PI3-Akt pathway plays a critical role in the regulation of eNOS phosphorylation and eNOS activity in response to hypoxia. We further conclude that hypoxia stimulates formation of a multiprotein complex containing phosphorylated eNOS, Akt, and Hsp90, suggesting that a coordinated interaction between Hsp90 and Akt may contribute to the increases in eNOS activity and NO production.

\section{Acknowledgement}

This study is supported by HL 49530 grant from the National Institutes of Health, National Heart, Lung and Blood Institute.

\section{References}

1 Moncada S, Palmer RM, Higgs EA. The discovery of nitric oxide as the endogenous nitrovasodilator. Hypertension 1988;12:365-372.

2 Le Cras TD, Xue C, Rengasamy A, et al. Chronic hypoxia upregulates endothelial and inducible NO synthase gene and protein expression in rat lung. Am J Physiol 1996;270:L164-L170.

3 Bouloumie A, Schini-Kerth VB, Busse R. Vascular endothelial growth factor up-regulates nitric oxide synthase expression in endothelial cells. Cardiovasc Res 1999;41:773-780.

4 Park KH, Rubin LE, Gross SS, et al. Nitric oxide is a mediator of hypoxic coronary vasodilatation. Relation to adenosine and cyclooxygenase-derived metabolites. Circ Res 1992;71:992-1001.

5 Thompson LP, Aguan K, Pinkas G, et al. Chronic hypoxia increases the NO contribution of acetylcholine vasodilation of the fetal guinea pig heart. Am J Physiol Regul Integr Comp Physiol 2000;279: R1813-R2018.

6 Hampl V, Cornfield DN, Cowan NJ, et al. Hypoxia potentiates nitric oxide synthesis and transiently increases cytosolic calcium levels in pulmonary artery endothelial cells. Eur Respir J 1995;8:515-522.

7 Justice JM, Tanner MA, Myers PR. Endothelial cell regulation of nitric oxide production during hypoxia in coronary microvessels and epicardial arteries. J Cell Physiol 2000;182:359-365.

8 Garcia-Cardena G, Fan R, Stern DF, et al. Endothelial nitric oxide synthase is regulated by tyrosine phosphorylation and interacts with caveolin-1. J Biol Chem 1996;271:27237-27240.

9 Werner-Felmayer G, Werner ER, Fuchs D, et al. Pteridine biosynthesis in human endothelial cells. Impact on nitric oxide-mediated formation of cyclic GMP. J Biol Chem 1993;268:1842-1846.

10 Shaul PW, Smart EJ, Robinson LJ, et al. Acylation targets endothelial nitric-oxide synthase to plasmalemmal caveolae. J Biol Chem 1996;271:6518-6522.

11 Forstermann U, Pollock JS, Schmidt HH, et al. Calmodulin-dependent endothelium-derived relaxing factor/nitric oxide synthase activity is present in the particulate and cytosolic fractions of bovine aortic endothelial cells. Proc Natl Acad Sci USA 1991; 88:1788-1792.

12 Garcia-Cardena G, Martasek P, Masters BS, et al. Dissecting the interaction between nitric oxide synthase (NOS) and caveolin. Functional significance of the nos caveolin binding domain in vivo. J Biol Chem 1997;272:25437-25440.

13 Garcia-Cardena G, Fan R, Shah V, et al. Dynamic activation of endothelial nitric oxide synthase by Hsp90. Nature 1998;392:821-824.

14 Fulton D, Gratton JP, McCabe TJ, et al. Regulation of endothelium-derived nitric oxide production by the protein kinase Akt. Nature 1999;399:597-601.

15 Gratton JP, Fontana J, O’Connor DS, et al. Reconstitution of an endothelial nitric-oxide synthase (eNOS), hsp90, and caveolin-1 complex in vitro. Evidence that hsp90 facilitates calmodulin stimulated displacement of eNOS from caveolin-1. J Biol Chem 2000;275: 22268-22272.

16 Brouet A, Sonveaux P, Dessy C, et al. Hsp90 ensures the transition from the early $\mathrm{Ca} 2+$-dependent to the late phosphorylation-dependent activation of the endothelial nitric-oxide synthase in vascular endothelial growth factor-exposed endothelial cells. J Biol Chem 2001;276:32663-32669.

17 Gerber HP, Condorelli F, Park J, et al. Differential transcriptional regulation of the two vascular endothelial growth factor receptor genes. Flt-1, but not Flk-1/ KDR, is up-regulated by hypoxia. J Biol Chem 1997;272:23659-23667.

18 Almgren CM, Olson LE. Moderate hypoxia increases heat shock protein 90 expression in excised rat aorta. J Vasc Res 1999;36:363-371. 
19 Luo Z, Fujio Y, Kureishi Y, et al. Acute modulation of endothelial Akt/PKB activity alters nitric oxide-dependent vasomotor activity in vivo. J Clin Invest 2000;106:493-499.

20 Isenovic E, Walsh MF, Muniyappa R, et al. Phosphatidylinositol 3-kinase may mediate isoproterenolinduced vascular relaxation in part through nitric oxide production. Metabolism 2002;51:380-386.

21 Northcott CA, Poy MN, Najjar SM, et al. Phosphoinositide 3-kinase mediates enhanced spontaneous and agonist-induced contraction in aorta of deoxycorticosterone acetate-salt hypertensive rats. Circ Res 2002;91:360-369.

22 Papapetropoulos A, Garcia-Cardena G, Madri JA, et al. Nitric oxide production contributes to the angiogenic properties of vascular endothelial growth factor in human endothelial cells. J Clin Invest 1997;100: 3131-3139.

23 Malek AM, Jiang L, Lee I, et al. Induction of nitric oxide synthase mRNA by shear stress requires intracellular calcium and G-protein signals and is modulated by PI 3 kinase. Biochem Biophys Res Commun 1999;254:231-242.

24 Michell BJ, Griffiths JE, Mitchelhill KI, et al. The Akt kinase signals directly to endothelial nitric oxide synthase. Curr Biol 1999;9:845-848.

25 Dimmeler S, Fleming I, Fisslthaler B, et al. Activation of nitric oxide synthase in endothelial cells by Akt-dependent phosphorylation. Nature 1999;399: 601-605.

$26 \mathrm{Xu}$ XP, Pollock JS, Tanner MA, et al. Hypoxia activates nitric oxide synthase and stimulates nitric oxide production in porcine coronary resistance arteriolar endothelial cells. Cardiovasc Res 1995;30:841-847.

27 Schulte TW, Akinaga S, Soga S, et al. Antibiotic radicicol binds to the $\mathrm{N}$-terminal domains of Hsp90 and shares important biologic activities with geldanamycin. Cell Stress Chaperones 1998;3:106-108.

28 Dudley DT, Pang L, Decker SJ, et al. A synthetic inhibitor of the mitogen-activated protein kinase cascade. Proc Natl Acad Sci USA 1995;92:7686-7689.

29 Chen JX, Berry LC, Tanner $M$, et al. Nitric oxide donors regulate nitric oxide synthase in bovine pulmonary artery endothelium. J Cell Physiol 2001; 186:116-123.

30 McCabe TJ, Fulton D, Roman LJ, et al. Enhanced electron flux and reduced calmodulin dissociation may explain 'calcium-independent' eNOS activation by phosphorylation. J Biol Chem 2000;275: 6123-6128.

31 Lerman A, Burnett Jr JC, Higano ST, et al. Long-term L-arginine supplementation improves small-vessel coronary endothelial function in humans. Circulation 1998;97:2123-2128.

32 Goumas G, Tentolouris C, Tousoulis D, et al. Therapeutic modification of the L-arginine-eNOS pathway in cardiovascular diseases. Atherosclerosis 2001;154: $255-267$.
33 Bose S, Weikl T, Bugl H, et al. Chaperone function of Hsp90-associated proteins. Science 1996;274: 1715-1717.

34 Yonehara M, Minami Y, Kawata Y, et al. Heat-induced chaperone activity of HSP90. J Biol Chem 1996; 271:2641-2645.

35 Harris MB, Ju H, Venema VJ, et al. Role of heat shock protein 90 in bradykinin-stimulated endothelial nitric oxide release. Gen Pharmacol 2000;35:165-170.

36 Fontana J, Fulton D, Chen Y, et al. Domain mapping studies reveal that the $\mathrm{M}$ domain of hsp90 serves as a molecular scaffold to regulate Akt-dependent phosphorylation of endothelial nitric oxide synthase and NO release. Circ Res 2002;90:866-873.

37 Shi Y, Baker JE, Zhang C, et al. Chronic hypoxia increases endothelial nitric oxide synthase generation of nitric oxide by increasing heat shock protein 90 association and serine phosphorylation. Circ Res 2002;91:300-306.

38 Boo YC, Sorescu G, Boyd N, et al. Shear stress stimulates phosphorylation of endothelial nitric-oxide synthase at Ser1179 by Akt-independent mechanisms: role of protein kinase A. J Biol Chem 2002;277: 3388-3396.

39 Hur E, Kim HH, Choi SM, et al. Reduction of hypoxiainduced transcription through the repression of hypoxia-inducible factor-1alpha/aryl hydrocarbon receptor nuclear translocator DNA binding by the $90-\mathrm{kDa}$ heat-shock protein inhibitor radicicol. Mol Pharmacol 2002;62:975-982.

40 Fujita N, Sato S, Ishida A, et al. Involvement of Hsp90 in signaling and stability of 3-phosphoinositide-dependent kinase-1. J Biol Chem 2002;277: 10346-10353.

41 Nimmanapalli R, O’Bryan E, Bhalla K. Geldanamycin and its analogue 17-allylamino-17-demethoxygeldanamycin lowers Bcr-Abl levels and induces apoptosis and differentiation of Bcr- Abl-positive human leukemic blasts. Cancer Res 2001;61:1799-1804.

42 Hostein I, Robertson D, DiStefano F, et al. Inhibition of signal transduction by the Hsp90 inhibitor 17-allylamino-17-demethoxygeldanamycin results in cytostasis and apoptosis. Cancer Res 2001;61:4003-4009.

43 Sato S, Fujita N, Tsuruo T. Modulation of Akt kinase activity by binding to Hsp90. Proc Natl Acad Sci USA 2000;97:10832-10837.

44 Chen Z, Yuhanna IS, Galcheva-Gargova Z, et al. Estrogen receptor alpha mediates the nongenomic activation of endothelial nitric oxide synthase by estrogen. J Clin Invest 1999;103:401-406.

45 Bernier SG, Haldar S, Michel T. Bradykinin-regulated interactions of the mitogen-activated protein kinase pathway with the endothelial nitric-oxide synthase. J Biol Chem 2000;275:30707-30715.

46 Go YM, Boo YC, Park H, et al. Protein kinase B/Akt activates c-Jun $\mathrm{NH}(2)$-terminal kinase by increasing NO production in response to shear stress. J Appl Physiol 2001;91:1574-1581. 